\title{
Fatigue strength improvement of Ti alloy with DLC coating
}

\author{
S.-I. Nishida ${ }^{1}$, N. Hattori ${ }^{1}$, Y. Nakabaru ${ }^{1} \&$ A. Tsuchiyama ${ }^{2}$ \\ ${ }^{I}$ Faculty of Science \& Engineering, Saga University, Saga City, Japan \\ ${ }^{2}$ Fukuoka Industrial Technology Center, Yahatanishi-ku, Kitakyushu, \\ Japan
}

\begin{abstract}
As is generally known, Titanium alloy has excellent properties for its lightweight, high strength ratio, high anti-corrosive resistance etc. On the other hand, as Ti alloy is not so good at wear resistance, there occasionally appear some problems at the contact area with the other metals. Therefore, surface treatment of $\mathrm{Ti}$ alloy would be one good solution for the above problems. Diamond-like carbon (DLC) would be one of the most practical methods for compensating the defect of Ti alloy's properties due to its high hardness, electrical insulation, resistance to chemical attacks, superior smooth surface, excellent wear resistance etc. Rotating bending fatigue tests had been performed in order to investigate the effect of DLC coating on the fatigue properties of Ti-6Al-4V alloy. The DLC films have been deposited on Ti alloy specimens using an ionization deposition method. Four kinds of specimens coated for different coating times were prepared for the fatigue test. The result obtained in this test shows that the fatigue limit and internal hardness improved as the coating time becomes longer and the fatigue limit was improved by $100 \mathrm{MPa}$ as compared to the specimen without surface treatment. It is considered that this result would be due to compressive residual stress generated in the specimen's surface during the process of the DLC coating.

Keywords: Ti alloy, fatigue strength, DLC film, hardness, fatigue crack initiation and propagation.
\end{abstract}




\section{Introduction}

Titanium alloys have been widely used in various kinds of industries because of their light and high specific tensile strength, excellent corrosion resistance etc. On the other hand, there exists a big limitation for their applications due to the high processing cost of Ti and its alloys [1]. One of this cost effective use will be to utilize its unique properties by combining with another techniques e.g. surface treatments. Many tests have been carried out in trying to improve the mechanical properties of $\mathrm{Ti}$ alloys by various kinds of surface treatments such as case hardening, plating, selective hardening, ion plating etc. [2-6]. In addition, some of the authors have also tried to improve the fatigue strength of Ti-6Al-4V alloy by ion-nitride, plasma flame, electron plating and plasma immersion DLC [7-9] and clarified that the fatigue limit of DLC specimens were improved by about $20 \%$ than that of the conventional Ti-6Al-4V. Therefore, the authors have focused to DLC coating on Ti-6Al-4V changing the coating time and analyzed the mechanism of fatigue strength improvement.

\section{Experimental procedure}

\subsection{Specimen}

The specimen used in this test is the most representative titanium alloy Ti-6Al$4 \mathrm{~V}$ alloy, of which chemical compositions are listed in Table1. Fig.1 shows the shape and dimensions of the fatigue specimen. All of the specimens were polished with emery paper (\#400-3000) and annealed at $600{ }^{\circ} \mathrm{C}$ for half an hour.

\subsection{Surface treatment}

The specimens were DLC coated with $\mathrm{C}_{6} \mathrm{H}_{6}$ gas changing the coating time. Table 2 lists the surface treatment conditions of DLC film. In addition, the specimen B1 was contaminated with Al substrate during Ar gas bombardment and this contaminated layer is considered to be the intermediate one whose thickness is $0.2 \mu \mathrm{m}$.

Table 1: $\quad$ Chemical composition (mass $\%)$.

\begin{tabular}{c|c|c|c|c|c|c}
\hline $\mathrm{Al}$ & $\mathrm{V}$ & $\mathrm{Fe}$ & $\mathrm{O}$ & $\mathrm{C}$ & $\mathrm{N}$ & $\mathrm{H}$ \\
\hline 6.1 & 4.2 & 0.15 & 0.14 & 0.011 & 0.010 & 0.0043 \\
\hline
\end{tabular}

\subsection{Testing machines and surface observation}

Ono-type rotating bending fatigue testing machine $(14.7 \mathrm{~N}-\mathrm{m})$ was used in this test under the repetition of $3000 \mathrm{rpm}$. The fracture surfaces were observed with an optical microscope and a scanning electron microscope (SEM). In addition, the vertical section of each modified surface was observed using SEM. The micro-Vickers hardness was measured under a load of $0.245 \mathrm{~N}$. 
Table 2: $\quad$ Surface treatment conditions of DLC film.

\begin{tabular}{|c|c|c|c|c|c|}
\hline & NST & B1 & D1 & D2 & D3 \\
\hline Ar bombardment & & \multicolumn{4}{|c|}{20 minutes per side without bias voltage } \\
\hline Source gas & & & \multicolumn{3}{|c|}{ Benzene } \\
\hline Benzene flow rate, $\mathrm{F} / \mathrm{sccm}$ & & & \multicolumn{3}{|c|}{10} \\
\hline Anode voltage, $\mathrm{V}_{\mathrm{a}} / \mathrm{V}$ & & & \multicolumn{3}{|c|}{50} \\
\hline Reflector voltage, $\mathrm{V}_{\mathrm{c}} / \mathrm{V}$ & & & \multicolumn{3}{|c|}{20} \\
\hline Filament current, $\mathrm{I}_{\mathrm{f}} / \mathrm{A}$ & & & \multicolumn{3}{|c|}{30} \\
\hline Working pressure, $\mathrm{P} / \mathrm{Pa}$ & & & \multicolumn{3}{|c|}{$2.7 \times 10^{-1}$} \\
\hline Coating time, $\mathrm{t} / \mathrm{min}$ & & & 18 & 35 & 53 \\
\hline
\end{tabular}

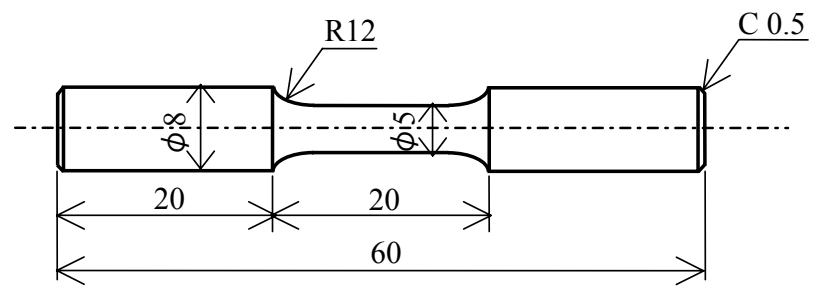

Figure 1: $\quad$ Shape and dimensions of fatigue specimen.

\section{Results and discussions}

\subsection{Hardness distribution and S-N curves}

Fig.2 shows the hardness testing results from a specimen's surface to its core under the load of $0.245 \mathrm{~N}$. The hardness number of NST (Non-surface treatment) specimen is HV320 and that of DLC specimen increased at the specimen's surface by about 1.5 times. From the hardness distribution pattern, it increased according to its coating time.

Fig. 3 shows the S-N curves. As the fatigue limit of NST specimen is $390 \mathrm{MPa}$, all of the specimens with DLC coating improve their fatigue limit, which also tends to increases with the coating time. The fatigue limit of D3 specimen shows the highest value being $500 \mathrm{MPa}$, which is higher than that of NST one by $30 \%$.

Fig. 4 shows the relation between fatigue limit or hardness and coating time. The hardness means the value at $10 \mu \mathrm{m}$ from the specimen's surface. According to this figure, the fatigue limit and hardness tend to be increased with coating time.

It is considered that the increase of hardness could be due to compressive residual stress which appeared in the surface layer with DLC coating. This compressive residual stress retards the crack propagation up to the inside of the specimen and improves the fatigue strength of coated specimens. This subject will be also discussed in section 3.4 later. 


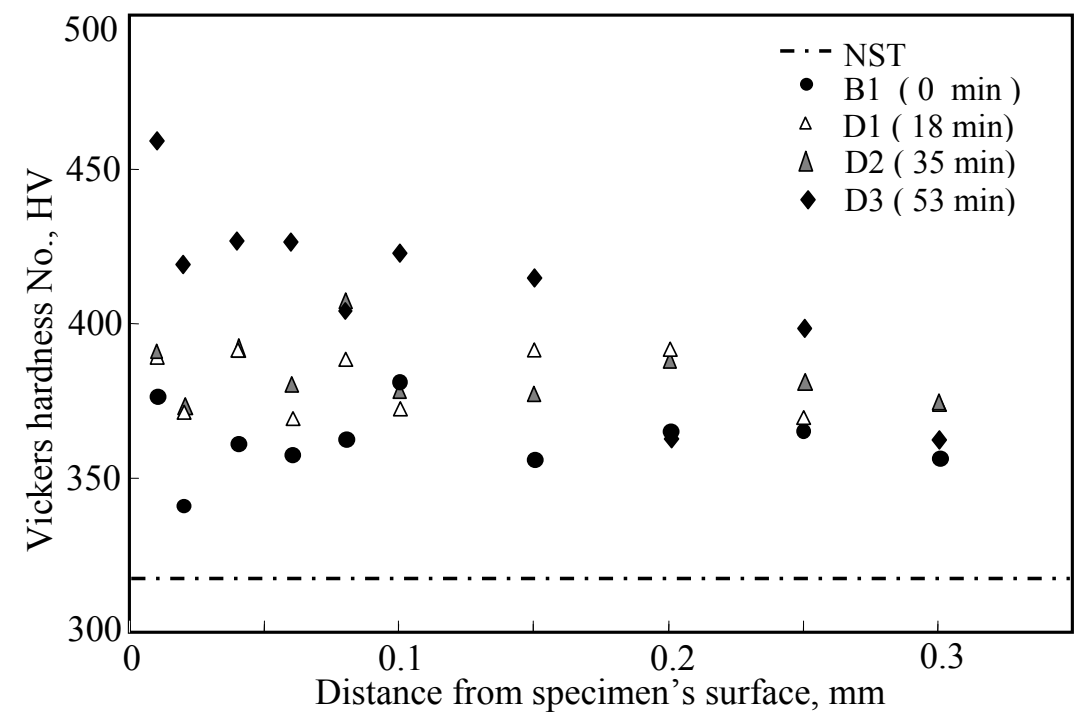

Figure 2: Hardness distribution from the specimen's surface.

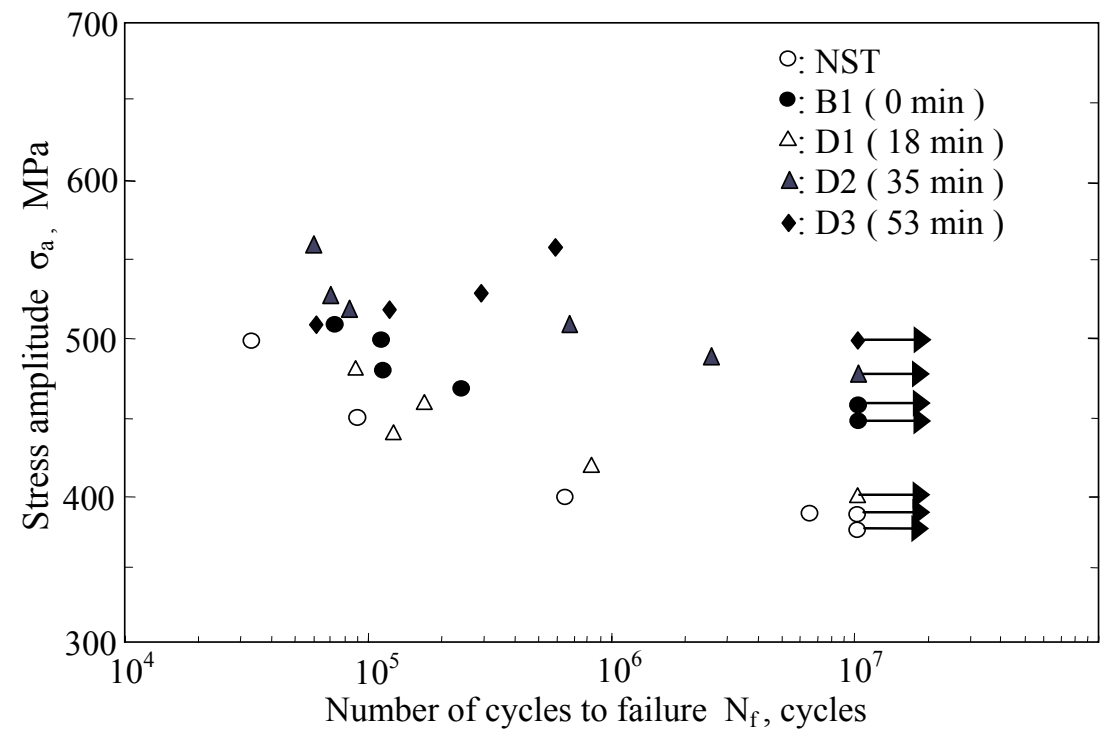

Figure 3: $\quad$ S-N curves. 


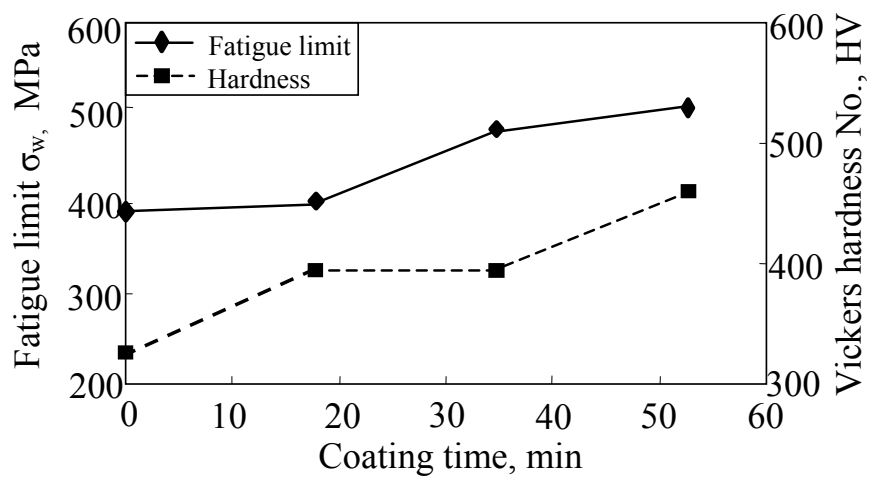

Figure 4: Relation between fatigue limit or hardness and coating time.

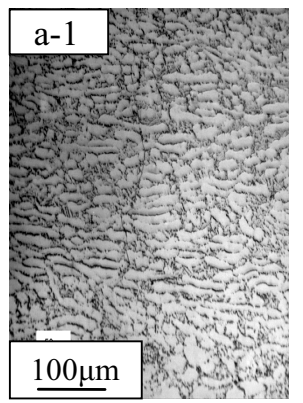

$\mathrm{N}=3.0 \times 10^{4}$

$\mathrm{N} / \mathrm{N}_{\mathrm{f}}=0.63$

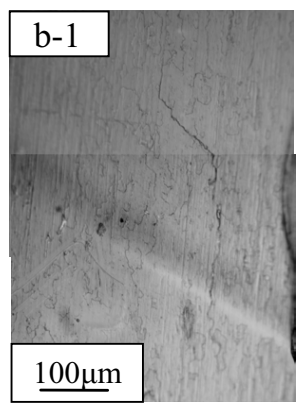

$\mathrm{N}=7.0 \times 10^{4}$

$\mathrm{N} / \mathrm{N}_{\mathrm{f}}=0.84$

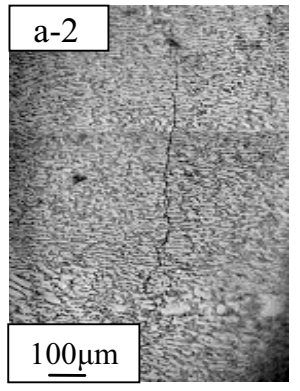

$\mathrm{N}=4.0 \times 10^{4}$

$\mathrm{N} / \mathrm{N}_{\mathrm{f}}=0.84$

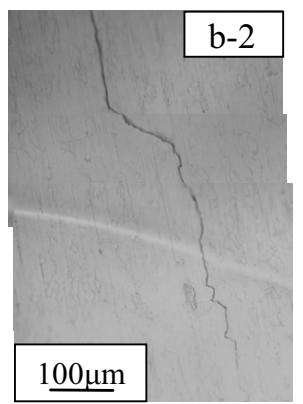

$\mathrm{N}=8.0 \times 10^{4}$

$\mathrm{N} / \mathrm{N}_{\mathrm{f}}=0.96$

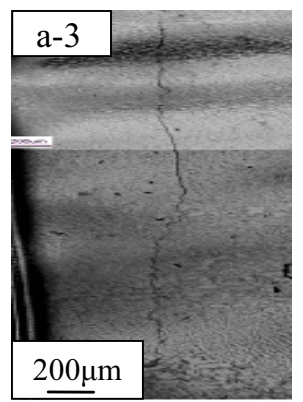

$\mathrm{N}=4.5 \times 10^{4}$

$\mathrm{N} / \mathrm{N}_{\mathrm{f}}=0.94$

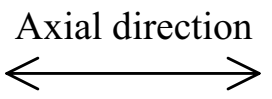

Figure 5: Fatigue crack of (a) NST specimen $\left(\sigma_{\mathrm{a}}=600 \mathrm{MPa}, \mathrm{N}_{\mathrm{f}}=4.8 \times 10^{4}\right.$ cycles) and (b) D2 specimen ( $\sigma_{\mathrm{a}}=520 \mathrm{MPa}, \mathrm{N}_{\mathrm{f}}=8.34 \times 10^{4}$ cycles $)$. 


\subsection{Fatigue crack propagation}

Fig.5 (a) shows the fatigue crack propagation of NST specimen. The fatigue micro-cracks are initiated at the cycle ratio about $53 \%$ and propagates to be a final fracture.

Fig.5 (b) shows the fatigue crack propagation of D2 specimen by the successive observation method at the specimen's surface. The fatigue microcracks are initiated at the cycle ratio of about $84 \%$ and propagates to be a final fracture. It is considered that this cycle ratio is very larger than that of NST specimen due to retarding effect by the compressive residual stress. It can be confirmed that the fatigue micro-cracks of D2 specimen are initiated by about 45 degree to the axial direction and propagate by about 90 degree to the axial direction. This feature is also observed in the NST specimen' surface. This result indicates that the fatigue micro-cracks of DLC coated specimen are initiated from the surface of the specimen at first, and then the cracks propagated into the core.

\subsection{Observation results of fracture surface}

Fig.6 shows the fracture surface of B1 specimen. The fatigue cracks initiate in the specimen's surface and propagate into the core direction.

Fig.7 shows the fracture surface of DLC coated specimen. Fig.7(b) is the magnified one of (a) indicated by arrow mark and this is coincided with the position as shown in Fig.5. The fatigue cracks initiate from the specimen's surface being the same as B1 specimen.

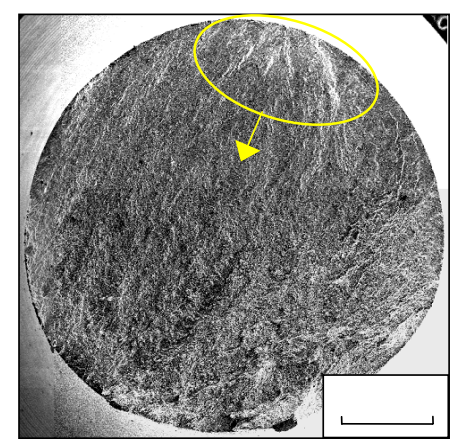

(a) Whole view

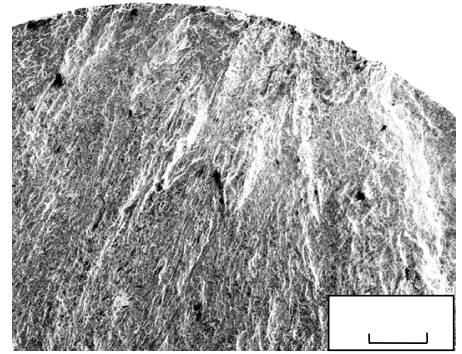

(b) Magnified (a)

Figure 6: Fracture surface of B1 specimen $\left(\sigma_{\mathrm{a}}=470 \mathrm{MPa}, \mathrm{N}_{\mathrm{f}}=2.4 \times 10^{5}\right.$ cycles). 


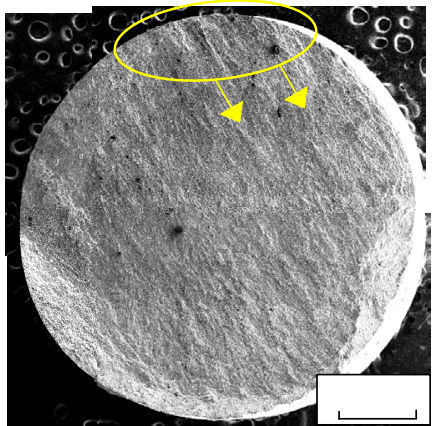

(a) Whole view

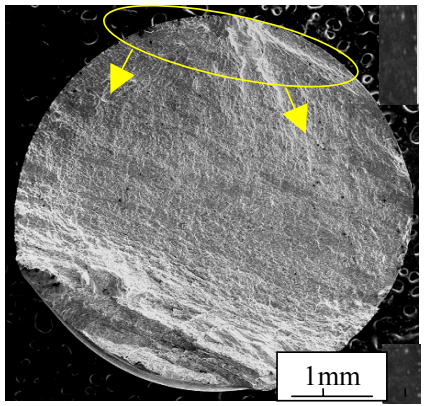

(c) Whole view

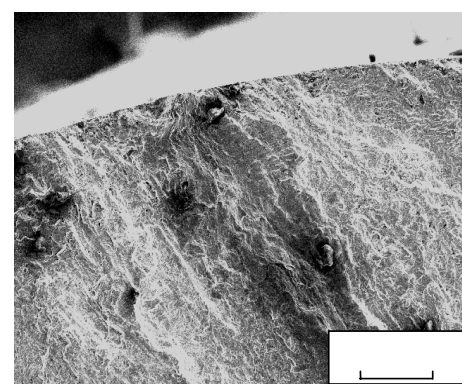

(b) Magnified (a)

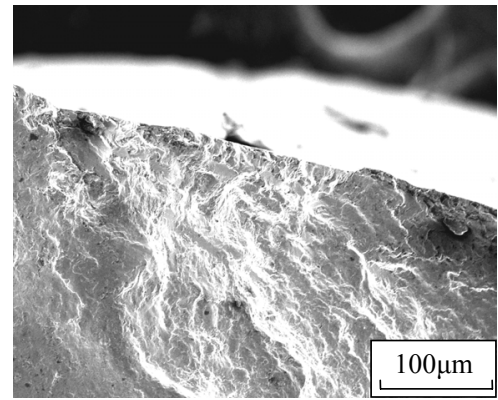

(d) Magnified (c)

Figure 7: Fracture surface of DLC coated specimen. (a) and (b) are D2 specimen $\left(\sigma_{\mathrm{a}}=520 \mathrm{MPa}, \mathrm{N}_{\mathrm{f}}=8.34 \times 10^{4}\right.$ cycles $),(\mathrm{c})$ and $(\mathrm{d})$ are D3 specimen $\left(\sigma_{\mathrm{a}}=520 \mathrm{MPa}, \mathrm{N}_{\mathrm{f}}=8.34 \times 10^{4}\right.$ cycles $)$.

\subsection{Compressive residual stress}

The authors have tried to measure the internal stress in the DLC film. But it was impossible to measure accurately due to the problem of specimen shape. Therefore, the case of DLC coated on the Si substrate was consulted in this paper. DLC film on the Si wafer had been deposited with the coating equipment being same as our testing condition. Fig. 8 shows the influence of the anode voltage on the internal stress in DLC films as a function of the film thickness [10]. The compressive residual stress of films deposited under the anode voltage of $50 \mathrm{~V}$ increases from about $2.5 \mathrm{MPa}$ to the maximum value of about $4.1 \mathrm{MPa}$. In contract with the case of $75 \mathrm{~V}$ and $100 \mathrm{~V}$, the internal stress becomes smaller according to the film thickness. These results indicate that DLC films prepared at anode voltage of $50 \mathrm{~V}$ could increase the compressive residual stress. 


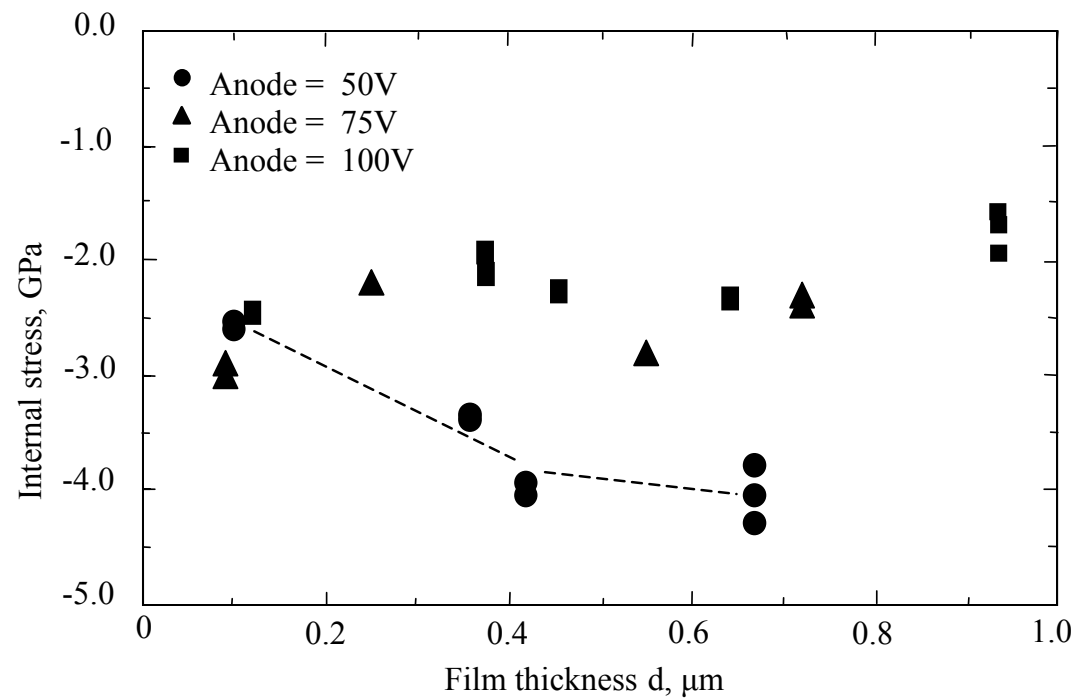

Figure 8: Relation between and film thickness and internal hardness [10].

As DLC films in our test were deposited under the voltage of $50 \mathrm{~V}$, it is considered that compressive residual stress was generated on the specimen's surface. In addition, the film thickness was increased with the coating time and the largest compressive residual stress was generated in D3 specimen's surface among all of the specimens.

\section{Conclusions}

The effect of DLC coating time on the fatigue properties of Ti-6Al-4V has been investigated and tried to analyze the mechanism of the improvement for the fatigue strength. The main results obtained in this test are as follows:

(1) From the Vickers hardness results, the DLC coated specimen show higher value than that of the conventional Ti-6Al-4V alloy due to the compressive residual stress. Especially, D3 specimen shows the highest value.

(2) DLC-2 and 3 specimens show the higher fatigue strength than that of the conventional Ti-6Al-4V by about $20 \%$ and $30 \%$, respectively. The fatigue limit and hardness tend to be increased with the coating time.

(3) The fatigue micro-cracks of DLC specimen are initiated from the specimen's surface and then propagate into the core. The crack initiation ratio is very larger than that of NST specimen due to the retardation effect by compressive residual stress.

\section{References}

[1] M.j.J.Donachie Jr. A Titanium technical guide, ASM International, (1988), p.9-19 
[2] J.M.Wiliuma \& R.A.Buchanan, Materials Science and Engineering, Vol.69, (1985), p.237-246

[3] E.J.Lee, R.G.Bayer, Metal finishing, (1985), p.39-42

[4] T.I.Wu and J.K.Wu, Metallurgical Transactions, Vol.24A, p.1181-1185

[5] J.A.Mock, Materials Engineering, Vol.80, (1974), p.101-108

[6] H.J.Gossman, D.J.Eaglesham et al, Applied Physics Letters, Vol.74, (1999), p.2435-2437

[7] S.Nishida, N.Hattori, Proc.of International Conference of Asian Pacific for Fracture \& Strength, 96, (1996), p.447-452

[8] S.Nishida, N.Hattori, Proc. Of International Conference on surface Treatment'97, (1997), p.199-209

[9] S.Nishida, S.Young, N.Hattori, \& A.Tsuchiyama, Proc.of Internal Conference on Surface Treatment'03, (2003), p1-12.

[10] A.Tsuchiyama, Y.Shima, H.Hasuyama, Proc.of Internal Conference on Surface Treatment'03, (2003), p41-49. 